\title{
Mesoscale Simulation Data for Initializing Fast-Time Wake Transport and Decay Models
}

\author{
Nash'at N. Ahmad", Fred H. Proctor ${ }^{\dagger}$, Randal L. VanValkenburg ${ }^{\ddagger}$, \\ NASA Langley Research Center, Hampton, Virginia, 23681 \\ Matthew J. Pruis ${ }^{\S}$ \\ NorthWest Research Associates, Redmond, Washington, 98052 \\ Fanny M. Limon Duparcmeur ${ }^{* *}$ \\ Metis Technology Solutions, Hampton, Virginia, 23681
}

\begin{abstract}
The fast-time wake transport and decay models require vertical profiles of crosswinds, potential temperature and the eddy dissipation rate as initial conditions. These inputs are normally obtained from various field sensors. In case of data-denied scenarios or operational use, these initial conditions can be provided by mesoscale model simulations. In this study, the vertical profiles of potential temperature from a mesoscale model were used as initial conditions for the fast-time wake models. The mesoscale model simulations were compared against available observations and the wake model predictions were compared with the Lidar measurements from three wake vortex field experiments.
\end{abstract}

\section{Nomenclature}

$\Gamma \quad=$ vortex circulation $\left(\mathrm{m}^{2} / \mathrm{s}\right)$

$\Gamma_{0} \quad=$ initial vortex circulation $\left(\mathrm{m}^{2} / \mathrm{s}\right)$

$V_{0} \quad=$ initial vortex descent velocity $(\mathrm{m} / \mathrm{s})$

$b_{0} \quad=$ initial vortex pair separation $(\mathrm{m})$

$N=$ dimensional Brunt-Väisälä frequency $\left(s^{-1}\right)$

$\varepsilon \quad=$ dimensional eddy dissipation rate $\left(\mathrm{m}^{2} / \mathrm{s}^{3}\right)$

$\theta \quad=$ potential temperature $(K)$

$T \quad=$ temperature $\left({ }^{\circ} F\right)$

$T_{\mathrm{d}} \quad=$ dew point temperature $\left({ }^{\circ} \mathrm{F}\right)$

$u \quad=$ east-west velocity component $(\mathrm{m} / \mathrm{s})$

$v \quad=$ north-south velocity component $(\mathrm{m} / \mathrm{s})$

\section{Introduction}

$\mathrm{F}$

AST-TIME wake transport and decay models are being developed and tested to provide solutions for safe and T efficient aircraft wake spacing standards. They are also needed for safety and capacity benefit studies of advanced air traffic management concepts and procedures. Most of the fast-time models (e.g., Sarpkaya 2000; Sarpkaya et al. 2001; Holzäpfel 2003; Proctor et al. 2006; Proctor 2009) require vertical profiles of temperature or potential temperature, crosswinds, and eddy dissipation rates (EDR) as initial conditions. These input weather conditions are usually obtained from various field sensors. For example, the crosswinds can be obtained from the Lidar or an instrumented meteorological tower, the temperature from microwave radiometers, and the EDR from sonic anemometers. A vertical profile of EDR can be generated based on the similarity theory (Han et al. 2000)

\footnotetext{
* Research Aerospace Engineer, NASA, Hampton, Virginia. Senior Member, AIAA.

${ }^{\dagger}$ Senior Research Scientist, NASA, Hampton, Virginia. Senior Member, AIAA.

* Research Scientist, NASA, Hampton, Virginia. Member, AIAA.

$\S$ Research Scientist, NWRA, Redmond, Washington. Member, AIAA.

*** Research Scientist, Metis Technology Solutions, Hampton, Virginia. Member, AIAA.
} 
provided that measurements are made at two different altitudes (e.g., from sonic anemometers mounted on a meteorological tower). Lidars can also be used to estimate the EDR (Pruis and Delisi 2011). Ideally, arrays of sensors could be deployed in the airport terminal area to provide spatially-varying information of different meteorological quantities. However, the cost of deploying a comprehensive array of sensors that can adequately cover the entire spatial extent of the terminal area is prohibitive and therefore measurements can typically be taken at just a few points in space. In addition, sensors cannot be used to forecast weather conditions several hours in advance.

Weather forecasts for supporting the terminal area operations can be obtained with the help of numerical models and substantial progress has been made in mesoscale modeling over the last three decades (Ahmad and Proctor 2012). The operational mesoscale weather models include the National Center for Atmospheric Research's (NCAR) Weather Research and Forecasting (WRF) model (Klemp et al. 2007), Science Applications International Corporation's Operational Multiscale Environment model with Grid Adaptivity (Bacon et al. 2000), the United States Navy's Coupled Ocean/Atmosphere Mesoscale Prediction System (Hodur 1997), and the National Centers for Environmental Prediction's (NCEP) Rapid Update Cycle (RUC) developed by Benjamin et al. (2004).

Several studies have been conducted in the past to evaluate mesoscale modeling for supporting terminal area operations (Kaplan et al. 1999; Charney et al. 2000; Kaplan et al. 2006; Frech et al. 2007; Gerz et al. 2007; Ringley et al. 2007; Ahmad and Proctor 2012). These studies have primarily focused on quantifying errors in mesoscale model forecasts. In the current study, the WRF mesoscale model was used to generate initial conditions of potential temperature for the fast-time wake vortex transport and decay models. The simulations were conducted for three different wake vortex field experiments. The fast-time models were run using initial conditions from the WRF forecast and from observations. The fast-time model predictions were then compared with Lidar data. In the following sections, the results of fast-time wake vortex models and the WRF simulations are described in detail.

\section{Fast-Time Wake Transport and Decay Models}

Fast-time wake models are empirical or semi-empirical algorithms used for real-time predictions of wake transport and decay based on aircraft parameters and ambient weather conditions. The aircraft dependent parameters include the initial vortex descent velocity $\left(V_{0}\right)$ and vortex pair separation distance $\left(b_{0}\right)$. The atmospheric initial conditions include vertical profiles of either temperature or potential temperature $(\theta)$, EDR $(\varepsilon)$ and crosswind. The atmospheric parameters that affect wake decay are atmospheric stratification and turbulence. The first fast-time wake transport and decay model was developed by Greene (1986). Some of the fast-time models currently in use include: AVOSS (Aircraft Vortex Spacing System) Prediction Algorithm (APA), TASS (Terminal Area Simulation System) Derived Algorithms for Wake Prediction (TDAWP), Probabilistic 2-Phased (P2P) model and the Deterministic wake Vortex Model (DVM). The APA model (Robins and Delisi 2002) incorporates Sarpkaya's model (Sarpkaya 2000; Sarpkaya et al. 2001) for out-of-ground-effect vortex decay and descent, and follows an approach similar to Corjon and Poinsot (1996) for in-ground-effect vortex transport. The TDAWP model (Proctor et al. 2006; Proctor and Hamilton 2009) has been developed from parametric studies using large eddy simulation of wake vortices. The APA and TDAWP models have been developed by the National Aeronautics and Space Administration (NASA), while the P2P model (Holzäpfel 2003) and the DVM (de Visscher et al. 2010 ) have been developed by the Deutsches Zentrum für Luft- und Raumfahrt (DLR) and Université catholique de Louvain (UCL), respectively.

\section{Mesoscale Modeling}

The WRF model is a mesoscale numerical weather prediction model that has been developed by NCAR with help from various partners in academia and federal research laboratories. It has governing equations for the timedependent, three-dimensional, nonhydrostatic, fully compressible Navier-Stokes equations. The model grid structure is based on Arakawa C-grid staggering (Arakawa and Lamb 1977). In the vertical, WRF uses a terrainfollowing pressure formulation, where the top of the domain is a constant pressure surface. The grid can be stretched in the vertical to provide higher resolution in the boundary layer. In the horizontal direction, one-way and two-way nesting options are available to provide high grid resolution in regions of interest. The horizontal and vertical advection terms can be discretized using schemes with second to sixth-order spatial accuracy. The time integration is done using an explicit third-order Runge-Kutta time marching scheme, with time-splitting of acoustic and gravity wave modes to maintain numerical stability. Choices for monotonic as well as positive-definite schemes are available for the advection of scalars. The latest version of WRF (Version 3.4) includes the option for a fifthorder Weighted Essentially Non-Oscillatory (WENO) scheme (Liu et al. 1994) for the advection of microphysical 
scalars and turbulence kinetic energy (TKE). Extensive physics packages for modeling the surface layer interactions, boundary layer turbulence processes, and cumulus parameterizations have been implemented in the model. Different cloud microphysics schemes of varying complexity are available, as well as parameterizations for radiation physics.

\section{Memphis Wake Vortex Field Experiment}

\section{A. Memphis Field Experiment}

A comprehensive field experiment to measure wake vortices and the ambient meteorological conditions was conducted at the Memphis International Airport in Memphis, Tennessee from August 6 through August 29, 1995 (Campbell, et al. 1997). The experiment was sponsored under NASA Langley Research Center's Aircraft Vortex Spacing System (AVOSS) project (Hinton 1995; Perry et al. 1997). Several sensor systems were deployed to collect detailed meteorological data to study the effects of atmospheric conditions on the behavior of wake vortices. The sensors included radiosondes, sodars, a wind profiler, one 150ft high meteorological tower, a Radio Acoustic Sounding System (RASS) and NASA Langley's OV-10 research aircraft. The radiosondes were used to measure winds and temperature measurements (10s averages) at $50 \mathrm{~m}$ vertical resolution. The OV-10 aircraft was flown at selected times and took measurements of temperature and winds at a sample rate of $10 \mathrm{~Hz}$. Temperature $(5 \mathrm{~min}$ averages) was measured using RASS every $30 \mathrm{~min}$ at 97 vertical levels from $145 \mathrm{~m}$ to $1492 \mathrm{~m}$. The $150 \mathrm{ft}$ ( $45.7 \mathrm{~m}$ ) meteorological tower was equipped with a large array of sensor systems. Winds, temperature and moisture were measured from the tower at $5 \mathrm{~m}, 10 \mathrm{~m}, 20 \mathrm{~m}, 30 \mathrm{~m}$, and $42 \mathrm{~m}$ heights. Turbulence quantities (turbulence kinetic energy and eddy dissipation rate) were estimated from wind measurements at $5 m$ and $40 m$ heights. Rain rate, soil temperature, soil moisture, barometric pressure, and incoming and outgoing solar radiation also were measured by the sensors deployed on the meteorological tower. Standard meteorological data such as atmospheric pressure, temperature, moisture, cloud cover, and visibility, etc. were obtained from the National Weather Service's Surface Aerodrome Observations (SAO) and the Automated Surface Observations System (ASOS).

\section{B. WRF Simulation Setup}

The WRF simulation domain consisted of an outermost domain bounded between $124.06^{\circ} \mathrm{W}$ and $55.93^{\circ} \mathrm{W}$ in longitude and $18.08^{\circ} \mathrm{N}$ and $49.14^{\circ} \mathrm{N}$ in latitude, with a horizontal mesh resolution of $36 \mathrm{~km}$. Two higher resolution nests were defined within the outermost domain. Domain 2 was bounded between $111.54^{\circ} \mathrm{W}$ and $68.45^{\circ} \mathrm{W}$ in longitude and $24.84^{\circ} \mathrm{N}$ and $43.86^{\circ} \mathrm{N}$ in latitude with a horizontal mesh resolution of $12 \mathrm{~km}$. The innermost domain was bounded between $99.74^{\circ} \mathrm{W}$ and $79.97^{\circ} \mathrm{W}$ in longitude and $30.66^{\circ} \mathrm{N}$ and $39.29^{\circ} \mathrm{N}$ in latitude with a horizontal mesh resolution of $4 \mathrm{~km}$. High-resolution $(1 \mathrm{~km})$ terrain and land use datasets were used for the innermost domain while lower resolution terrain was used in the coarser nests. A stretched grid with 60 levels was used in the vertical to provide high-resolution grid spacing in the boundary layer. The WRF computational domain for Memphis is shown in Figure 1.

The fifth-order upwind-biased scheme was used in the horizontal and the third-order upwind-biased scheme was used in the vertical within a three-stage Runge-Kutta explicit time-marching scheme. The monotonic scheme option was used for the transport of both the microphysical scalars and the TKE. The Rapid Radiative Transfer Model (RRTM) longwave radiation scheme (Mlawer et al. 1997) and the Goddard shortwave scheme (Chou and Suarez 1999) were used to parameterize the effects of both longwave and shortwave radiative transfer in the atmosphere. The Thompson scheme (Thompson et al. 2004) was used for the microphysics, and the cumulus parameterization schemes were switched off for the simulations. Mellor-Yamada-Janjić turbulence scheme was used to parameterize subgrid scale turbulent processes. The simulation was initialized for August 15, 1995 at 1800UTC using the North American Regional Reanalysis (Mesinger et al. 2006) data from the National Climate Data Center (NCDC) and was run for a $30 \mathrm{hr}$ forecast (spin-up of $6 \mathrm{hr}$ ). Data from the high-resolution innermost nest were output every $15 \mathrm{~min}$.

\section{Comparison of WRF Predicted Temperature and Winds with Observations}

The WRF simulation results were evaluated against available observations. Figure 2 shows the comparison of simulated surface temperatures and winds with the ASOS data and the SAVPAK sensors mounted on the met tower. Forecast errors were quantified in terms of root-mean-square error ( $\mathrm{rmse}$ ), mean absolute error (mae), and mean bias. These errors for the twenty-four hour period at Memphis are listed in Table 1. Overall, the WRF model performed well and was able to simulate the main features of the diurnal cycle for August 16, 1995. The surface temperature, dew point temperature and wind predictions from the model were in good agreement with observations at Memphis, both qualitatively as well as quantitatively. 


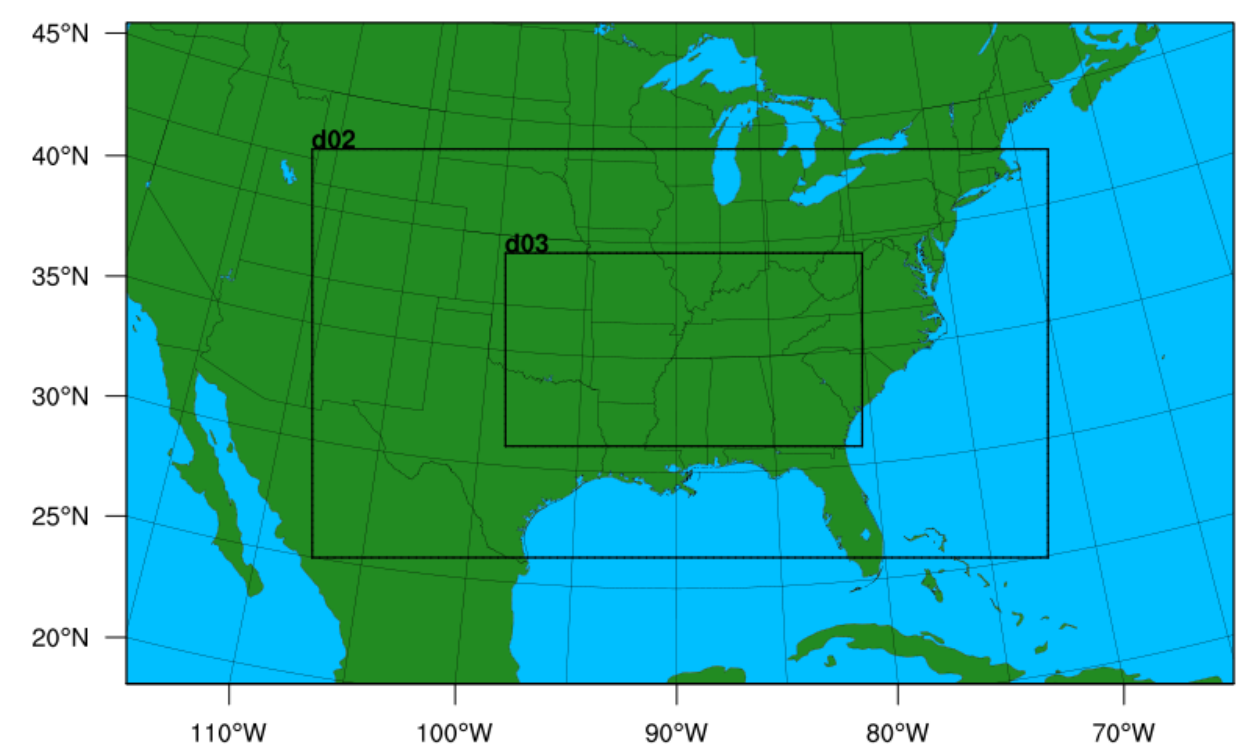

Figure 1. The WRF computational domain with higher resolution nests. The innermost nest had a resolution of $4 \mathrm{~km}$ and was centered at Memphis, Tennessee.
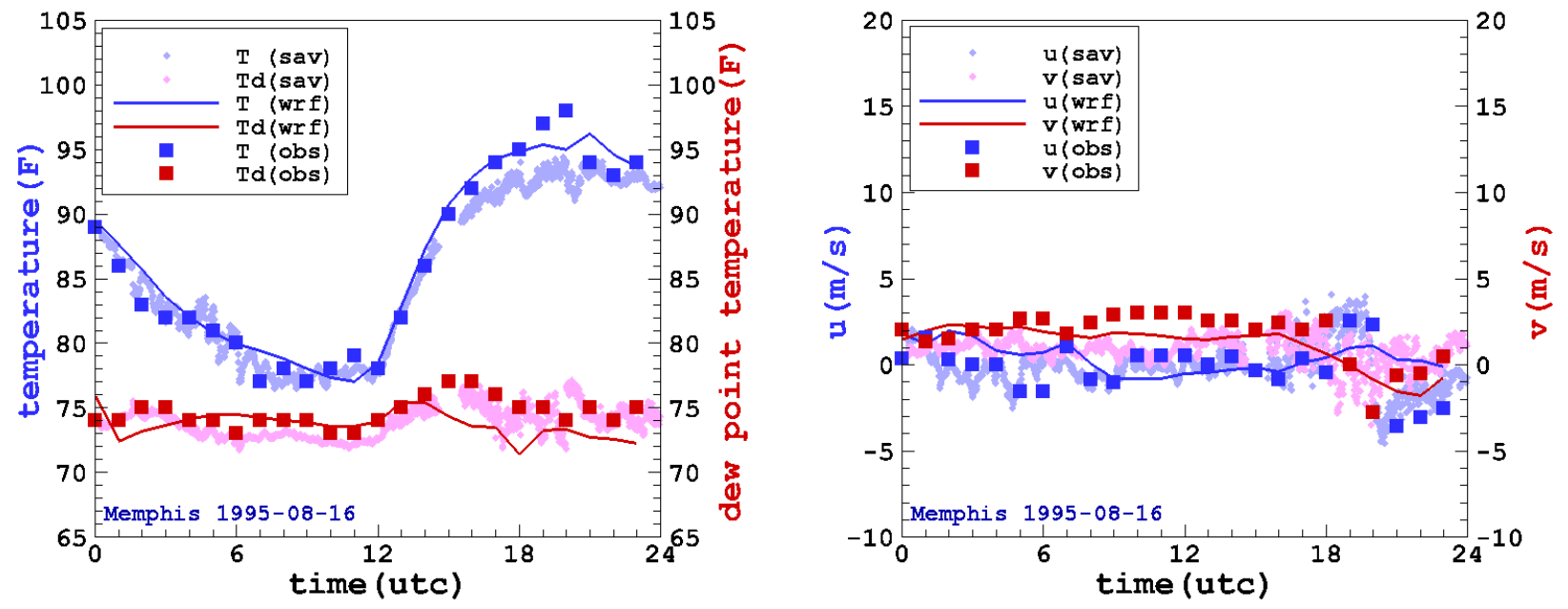

Figure 2. Comparison of WRF simulations with observations. WRF simulation results are denoted by solid lines. Observed temperatures at $\mathbf{2 m}$ for Memphis are shown as squares. Observed winds at $10 \mathrm{~m}$ for Memphis are depicted by squares. The SAVPAK $5 \mathrm{~m}$ data is given by small diamonds in the figure. The SAVPAK data frequency was every one minute.

Table 1: WRF Surface Forecast Errors for Memphis, Tennessee (August 16, 1995)

\begin{tabular}{|c|c|c|c|c|c|c|c|c|c|c|c|c|}
\hline \multirow{2}{*}{ case } & \multicolumn{3}{|c|}{$\mathrm{T}\left({ }^{\circ} \mathbf{F}\right)$} & \multicolumn{3}{c|}{$\mathrm{T}_{\mathrm{d}}\left({ }^{\circ} \mathbf{F}\right)$} & \multicolumn{3}{c|}{$\mathrm{u}(\mathrm{m} / \mathrm{s})$} & \multicolumn{3}{c|}{$\mathrm{v}(\mathrm{m} / \mathrm{s})$} \\
\cline { 2 - 13 } & rmse & mae & bias & rmse & mae & bias & rmse & mae & bias & rmse & mae & bias \\
\hline $\mathbf{1 9 9 5 - 0 8 - 1 6}$ & $\mathbf{1 . 4 0}$ & $\mathbf{1 . 1 5}$ & $\mathbf{0 . 8 1}$ & $\mathbf{1 . 3 7}$ & $\mathbf{1 . 0 2}$ & $\mathbf{- 0 . 6 6}$ & $\mathbf{1 . 6 8}$ & $\mathbf{1 . 3 2}$ & $\mathbf{0 . 7 4}$ & $\mathbf{0 . 8 8}$ & $\mathbf{0 . 7 4}$ & $\mathbf{- 0 . 4 3}$ \\
\hline
\end{tabular}




\section{Fast-Time Wake Transport and Decay Model Results}

There were a total of 46 landings for August 16, 1995, in the AVOSS database. Wake transport and decay predictions were obtained from three fast-time models (APA3.2, APA3.4, and TDP2.1) for each of the events using known aircraft parameters and inputs of crosswind, temperature, and turbulence. Two sets of simulations were conducted for each fast-time model: 1) the vertical profile potential temperature from observations was used, and 2) the vertical profile of the WRF-predicted potential temperature was used. The potential temperature profiles in the AVOSS database were generated by fusing data from several sensors. A comparison of the average Brunt-Väisälä frequency from the observations and the WRF forecast is shown in Figure 3.

The fast-time model predictions were then evaluated using Continuous Wave (CW) Lidar observations. The results were quantified in terms of root-mean-square error, and are given in Table 2. The circulation error was normalized by the initial circulation strength and the errors in lateral and vertical transport were normalized by the initial vortex separation, $b_{0}$. All three models had relatively low errors for circulation and lateral transport.

A comparison of the TDP2.1 wake predictions with CW Lidar data is shown in Figures 4-5. The generating aircraft in this case was a DC10 and the time corresponds to the nighttime stable boundary layer. The TDP2.1 simulations (initialized by observations and the WRF data) of circulation decay and vortex descent compare well with the Lidar measurements.

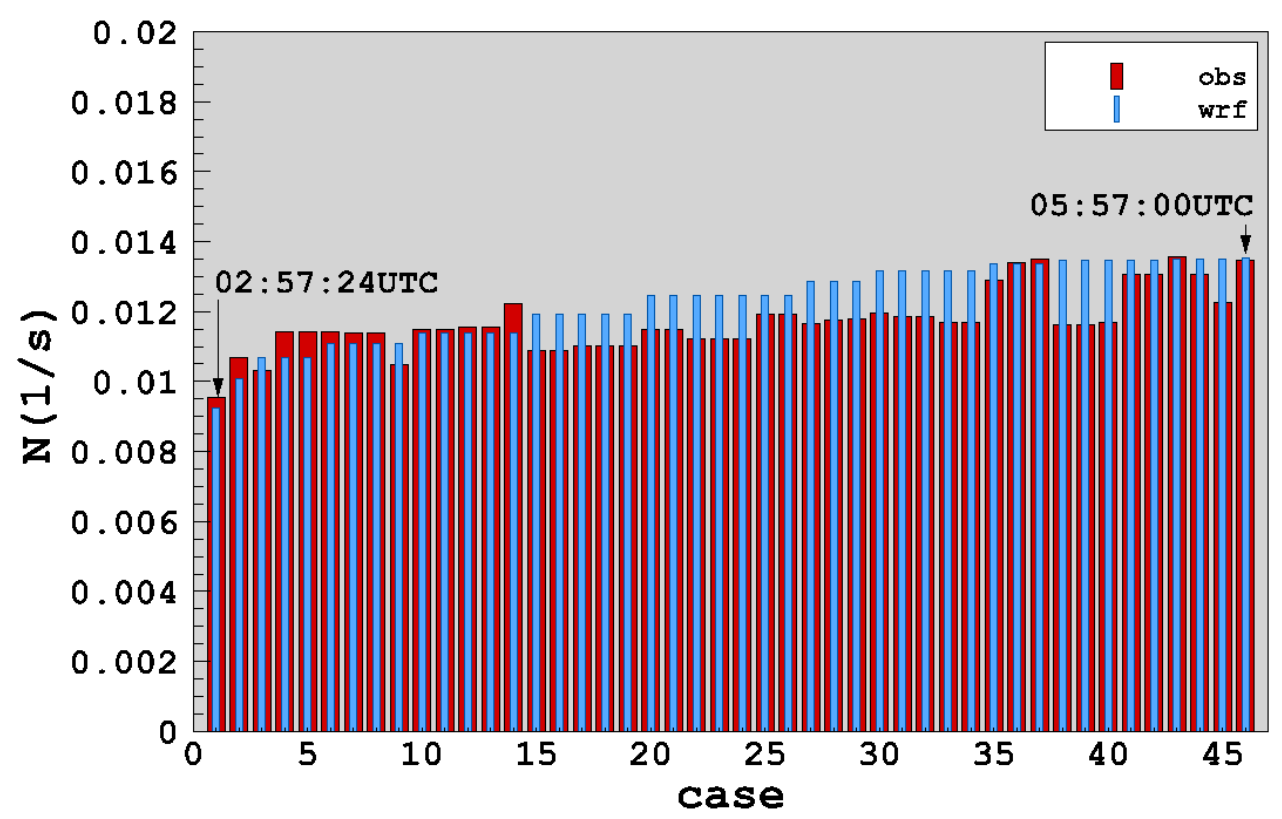

Figure 3. Comparison of the average Brunt-Väisälä frequency, $N\left(\mathrm{~s}^{-1}\right)$ for each vertical profile obtained from the WRF simulation and the observations. Memphis - August 16, 1995.

Table 2: Fast-Time Models Evaluation (Mean RMSE) - Memphis: August 16, 1995 (46 Cases)

\begin{tabular}{|c|c|c|c|c|c|c|}
\hline \multirow{2}{*}{ Model } & \multicolumn{2}{|c|}{$\begin{array}{c}\text { Circulation } \\
\text { (normalized by } \Gamma_{0}\end{array}$} & \multicolumn{2}{c|}{$\begin{array}{c}\text { Lateral Transport } \\
\left(\text { normalized by } \boldsymbol{b}_{0}\right.\end{array}$} & \multicolumn{2}{c|}{$\begin{array}{c}\text { Altitude } \\
\text { (normalized by } \boldsymbol{b}_{0} \text { ) }\end{array}$} \\
\cline { 2 - 7 } & ICs from OBS & $\theta$ from WRF & ICs from OBS & $\theta$ from WRF & ICs from OBS & $\theta$ from WRF \\
\hline TDP2.1 & $\mathbf{0 . 2 1 1}$ & $\mathbf{0 . 2 1 0}$ & $\mathbf{0 . 7 0 6}$ & $\mathbf{0 . 7 0 4}$ & $\mathbf{0 . 4 8 8}$ & $\mathbf{0 . 4 8 4}$ \\
\hline APA3.2 & $\mathbf{0 . 1 6 5}$ & $\mathbf{0 . 1 6 7}$ & $\mathbf{0 . 6 4 5}$ & $\mathbf{0 . 6 4 4}$ & $\mathbf{0 . 5 0 6}$ & $\mathbf{0 . 5 0 1}$ \\
\hline APA3.4 & $\mathbf{0 . 1 6 2}$ & $\mathbf{0 . 1 6 2}$ & $\mathbf{0 . 6 4 1}$ & $\mathbf{0 . 6 4 0}$ & $\mathbf{0 . 5 0 4}$ & $\mathbf{0 . 5 0 3}$ \\
\hline
\end{tabular}



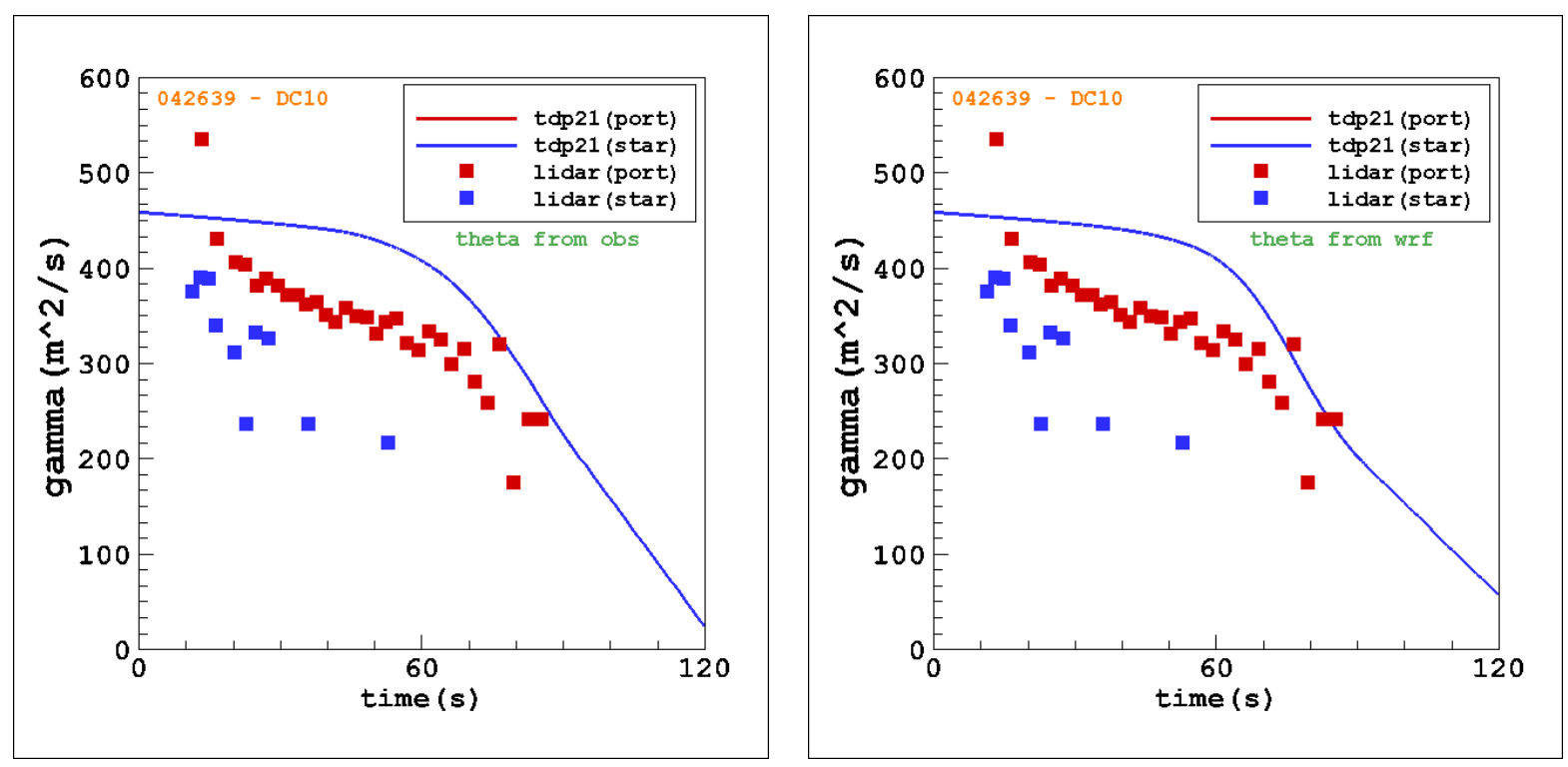

Figure 4. Comparison of TDP2.1 predicted wake vortex time histories with the observed CW Lidar data. The generating aircraft was a DC10 by observed potential temperature. The right panel shows TDP2.1 simulation initialized by WRF predicted potential temperature. Memphis - August 16, 1995.
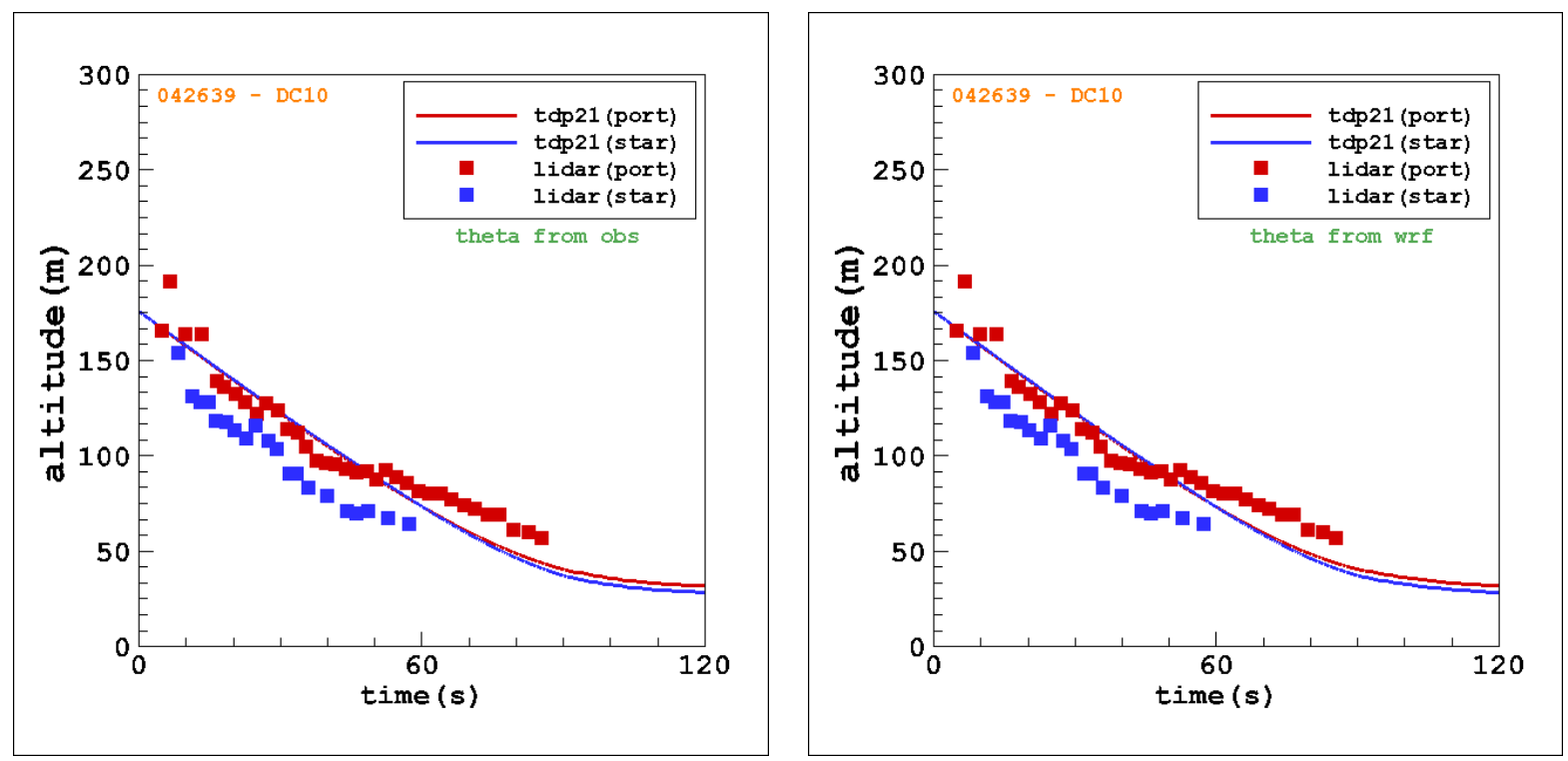

Figure 5. Comparison of TDP2.1 predicted wake vortex time histories with the observed CW Lidar data. The generating aircraft was a DC10 in this case. The left panel shows TDP2.1 simulation initialized by observed potential temperature. The right panel shows TDP2.1 simulation initialized by WRF predicted potential temperature. Memphis - August 16, 1995. 


\section{Dallas-Fort Worth Wake Vortex Field Experiment}

\section{A. Dallas-Fort Worth Field Experiment}

In 1997, the AVOSS (Hinton 1995; Perry et al. 1997) setup at Memphis International Airport was relocated to Dallas-Fort Worth International Airport. The primary objective of this field deployment was to conduct a comprehensive test of various AVOSS procedures established at Memphis (Dasey et al. 1998; Joseph et al. 1999). Wake measurements were obtained from NASA's $2 \mu \mathrm{m}$ pulsed Lidar, the Lincoln Labs' $10.6 \mu \mathrm{m}$ Continuous Wave Lidar and an array of anemometers (windline). One of the objectives was to collect meteorological data for the validation of mesoscale models and therefore an impressive array of meteorological sensors was deployed to quantify the atmospheric state in detail. Two meteorological towers were installed during this field experiment. Each meteorological tower was equipped with various sensor systems for the measurement of temperature, relative humidity, wind speed, and wind direction at different heights. Turbulence measurements were taken with sonic anemometers which measured the three components of wind at $10 \mathrm{~Hz}$. Several sensors were mounted at the base of each tower to measure the atmospheric pressure, rainfall, and solar radiation, etc. In addition to the two meteorological towers, a wind profiler, a RASS and a sodar were also deployed. Special upper air soundings were taken six times a day from five different sites surrounding the Dallas-Fort Worth International Airport. Standard meteorological data such as atmospheric pressure, temperature, moisture, cloud cover, and visibility, etc. were obtained from the National Weather Service's SAO and the ASOS data.

\section{B. WRF Simulation Setup}

Three levels of grid nesting were used in the simulation in order to achieve acceptable grid resolution while maintaining computational efficiency. The WRF simulation domain consisted of an outermost domain bounded between $129.16^{\circ} \mathrm{W}$ and $64.91^{\circ} \mathrm{W}$ in longitude and $13.44^{\circ} \mathrm{N}$ and $50.10^{\circ} \mathrm{N}$ in latitude with a horizontal mesh resolution of $36 \mathrm{~km}$. The innermost high resolution domain was centered at Dallas-Fort Worth, Texas and bounded between $102.73^{\circ} \mathrm{W}$ and $90.67^{\circ} \mathrm{W}$ in longitude and $29.26^{\circ} \mathrm{N}$ and $36.92^{\circ} \mathrm{N}$ in latitude with a horizontal mesh resolution of $4 \mathrm{~km}$. High-resolution $(1 \mathrm{~km})$ terrain and land use datasets were used for the innermost domain while lower resolution terrain was used in the coarser outer nest. A stretched grid with 60 levels was used in the vertical to provide high-resolution grid spacing in the boundary layer. The WRF computational domain is shown in Figure 6.

The Mellor-Yamada-Janjić turbulence scheme (Mellor and Yamada 1978; Janjić 1994) was used to parameterize sub-grid scale processes and higher-order schemes were used for computing the convective fluxes (fifth-order upwind-biased in the horizontal and third-order upwind-biased in the vertical). A fifth-order WENO scheme with positive definite limiter was used to transport microphysical scalars as well as turbulence kinetic energy. The option of WENO schemes is available in the latest distribution of the WRF model (Version 3.4). The simulation was initialized using the North American Regional Reanalysis (Mesinger et al. 2006) data from the NCDC at 0000UTC on October 3, 1997 and was run for a $24 h r$ forecast. Data from the high-resolution innermost nest were output every 15 min.

\section{Comparison of WRF Predicted Temperature and Winds with Observations}

Four previous studies have focused on the meteorological aspects of the AVOSS deployment at Dallas-Fort Worth (Kaplan et al. 1999; Charney et al. 2000; Kaplan et al. 2006; Ringley et al. 2007). Kaplan et al. (1999) discussed the formation of the Great Plains low level nocturnal jet and the ability of mesoscale models to accurately simulate the phenomenon. Charney et al. (2000) and Ringley et al. (2007) evaluated the accuracy of turbulence kinetic energy and EDR prediction from mesoscale models. In Kaplan et al. (2006) surface temperature and dew point temperature errors $\left(\sim 1^{\circ} \mathrm{C}\right)$ were estimated from surface maps for one data point only on two different days (September 18, 1997 1200UTC and September 19, 1997 1200UTC). An error analysis for the complete diurnal cycle using surface observations was not reported in any of these studies. In this study, the WRF simulation was run specifically to provide initial conditions of potential temperature for the fast-time models and therefore, the WRF simulation results were first evaluated against available observations. Figure 7 shows the comparison of simulated surface temperatures and winds with the ASOS data. Forecast errors were quantified in terms of root-mean-square error (rmse), mean absolute error (mae), and mean bias. These errors for the twenty-four hour period at Dallas-Fort Worth are listed in Table 3. Overall, the WRF model preformed reasonably well for October 3, 1997. The errors for the Dallas-Fort Worth simulation were larger for temperature and dew point temperature (compared to the Memphis simulation) but similar for the $u$ and $v$ components of the wind. 


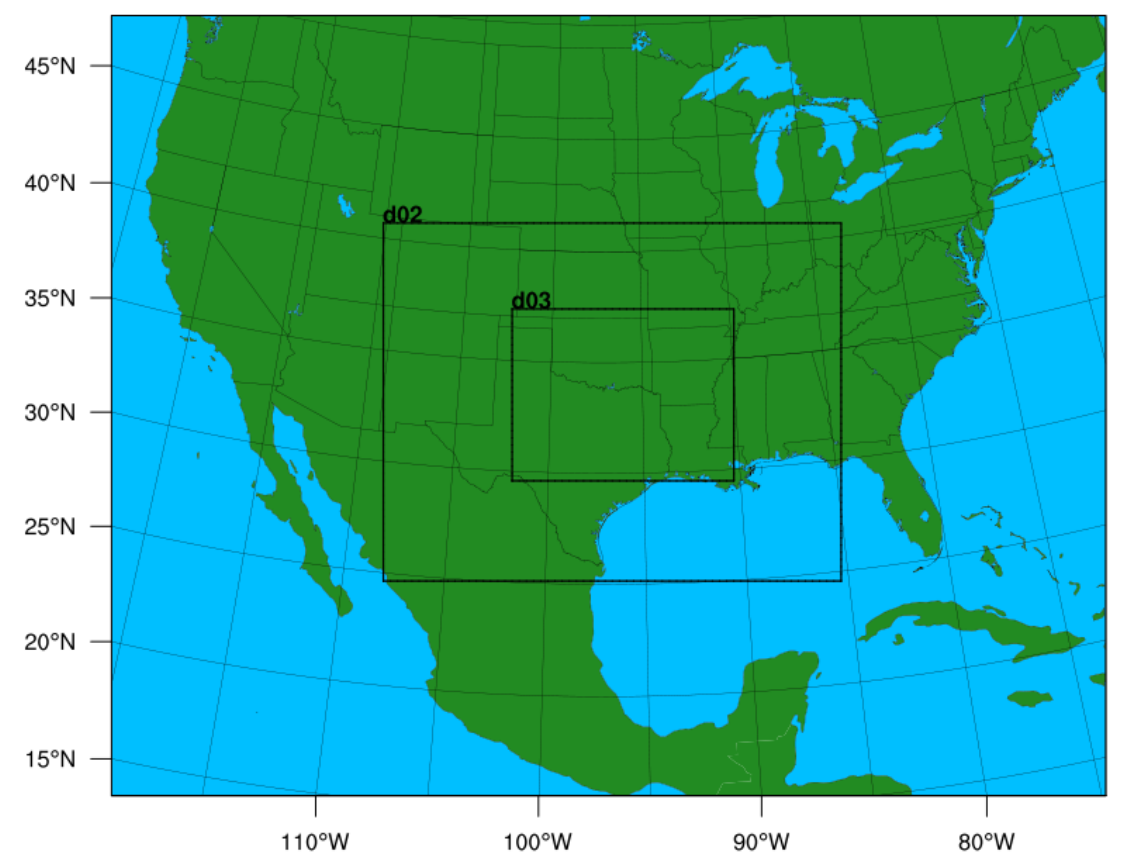

Figure 6. The WRF computational domain with higher resolution nests. The innermost nest had a resolution of $4 \mathrm{~km}$ and was centered at Dallas-Fort Worth, Texas.
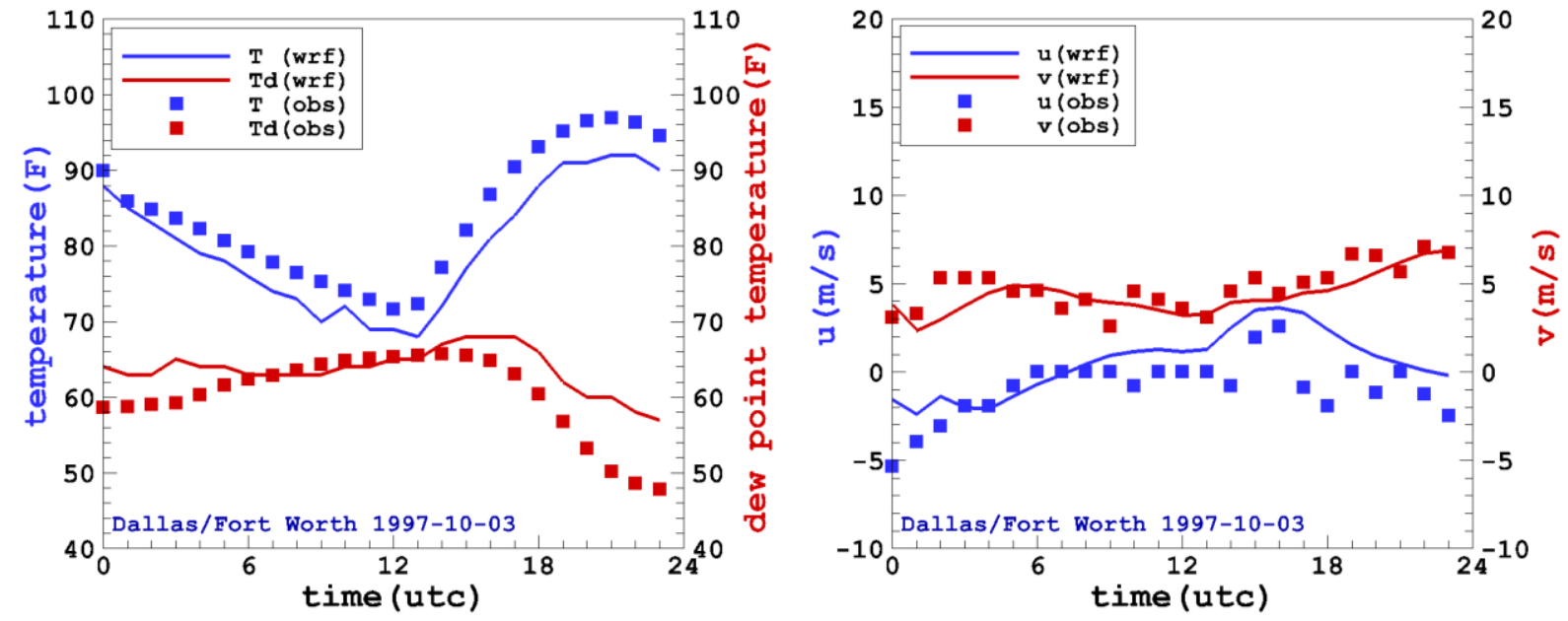

Figure 7. Comparison of WRF simulations with observations. WRF simulation results are denoted by solid lines. Observed temperatures at $2 \mathrm{~m}$ and observed winds at $10 \mathrm{~m}$ for Dallas-Fort Worth are shown as squares.

Table 3: WRF Surface Forecast Errors for Dallas-Fort Worth, Texas (October 3, 1997)

\begin{tabular}{|c|c|c|c|c|c|c|c|c|c|c|c|c|}
\hline \multirow{2}{*}{ case } & \multicolumn{3}{|c|}{$\mathbf{T}\left({ }^{\circ} \mathbf{F}\right)$} & \multicolumn{3}{|c|}{$\mathbf{T}_{\mathrm{d}}\left({ }^{\circ} \mathbf{F}\right)$} & \multicolumn{3}{|c|}{$\mathbf{u}(\mathbf{m} / \mathbf{s})$} & \multicolumn{3}{|c|}{$\mathbf{v}(\mathbf{m} / \mathbf{s})$} \\
\hline & rmse & bias & mae & rmse & bias & mae & rmse & bias & mae & rmse & bias & mae \\
\hline 1997-10-03 & 4.11 & 3.87 & 3.87 & 4.72 & -3.30 & 3.70 & 1.98 & 1.43 & 1.58 & 0.93 & -0.39 & 0.76 \\
\hline
\end{tabular}




\section{Fast-Time Wake Transport and Decay Model Results}

There were a total of 42 landings for October 3, 1997 for Dallas-Fort Worth in the AVOSS database. Wake transport and decay predictions were obtained from three fast-time models (APA3.2, APA3.4, and TDP2.1) for each of the events using known aircraft parameters and inputs of crosswind, temperature, and turbulence. The potential temperature profiles in the AVOSS database were generated by fusing data from several sensors. Two sets of simulations were conducted for each fast-time model: 1) the vertical profile potential temperature from observations was used, and 2) the vertical profile of the WRF-predicted potential temperature was used. A comparison of the average Brunt-Väisälä frequency from the observations and the WRF forecast is shown in Figure 8.

The fast-time model predictions were then evaluated using Continuous Wave (CW) Lidar observations. The results were quantified in terms of root-mean-square error, and are given in Table 4. The events on October 3, 1997 were mostly in near-ground effect (NGE). In the proximity of ground, stratification plays a secondary role in circulation decay of wakes. This is reflected in almost identical results obtained using the observed potential temperature and WRF predicted potential temperature (Table 4).

A comparison of the TDP2.1 wake predictions with CW Lidar data is shown in Figures 9-10. The generating aircraft in this case was a B752. The TDP2.1 predictions (initialized by observations and the WRF data) of circulation decay and vortex altitude compare well with the Lidar measurements.

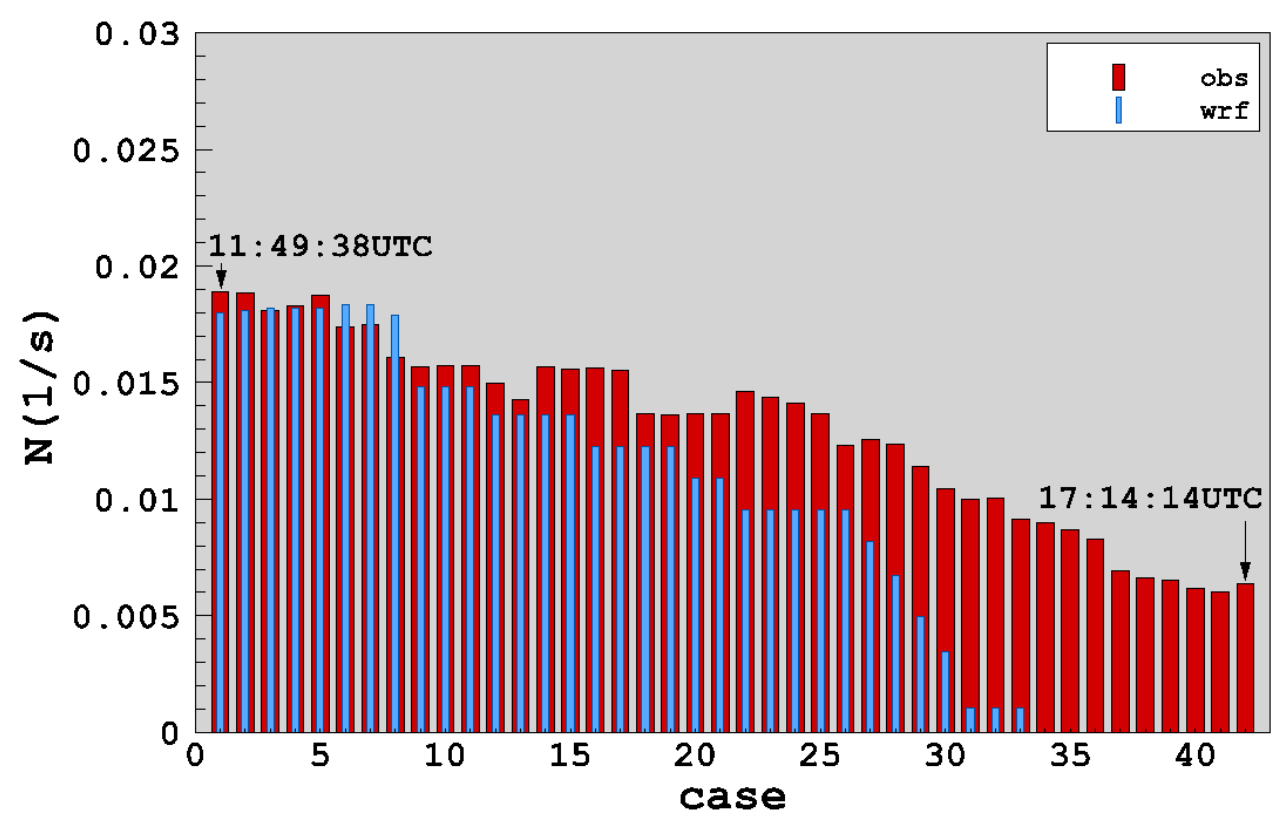

Figure 8. Comparison of the average Brunt-Väisälä frequency, $N\left(\mathrm{~s}^{-1}\right)$ for each vertical profile obtained from the WRF simulation and the observations. Dallas-Fort Worth - October 3, 1997.

Table 4: Fast-Time Models Evaluation (Mean RMSE) - Dallas-Fort Worth: October 3, 1997 (42 Cases)

\begin{tabular}{|c|c|c|c|c|c|c|}
\hline \multirow{2}{*}{ Model } & \multicolumn{2}{|c|}{$\begin{array}{c}\text { Circulation } \\
\text { (normalized by } \Gamma_{0} \text { ) }\end{array}$} & \multicolumn{2}{c|}{$\begin{array}{c}\text { Lateral Transport } \\
\left(\text { normalized by } \boldsymbol{b}_{0} \text { ) }\right.\end{array}$} & \multicolumn{2}{c|}{$\begin{array}{c}\text { Altitude } \\
\text { (normalized by } \boldsymbol{b}_{0} \text { ) }\end{array}$} \\
\cline { 2 - 7 } & ICs from OBS & $\theta$ from WRF & ICs from OBS & $\theta$ from WRF & ICs from OBS & $\theta$ from WRF \\
\hline TDP2.1 & $\mathbf{0 . 2 3 3}$ & $\mathbf{0 . 2 3 3}$ & $\mathbf{0 . 7 9 2}$ & $\mathbf{0 . 7 9 2}$ & $\mathbf{0 . 2 7 8}$ & $\mathbf{0 . 2 7 8}$ \\
\hline APA3.2 & $\mathbf{0 . 2 4 5}$ & $\mathbf{0 . 2 4 5}$ & $\mathbf{0 . 7 2 8}$ & $\mathbf{0 . 7 2 8}$ & $\mathbf{0 . 2 6 7}$ & $\mathbf{0 . 2 6 6}$ \\
\hline APA3.4 & $\mathbf{0 . 2 2 9}$ & $\mathbf{0 . 2 2 9}$ & $\mathbf{0 . 7 2 8}$ & $\mathbf{0 . 7 2 8}$ & $\mathbf{0 . 2 7 0}$ & $\mathbf{0 . 2 7 0}$ \\
\hline
\end{tabular}



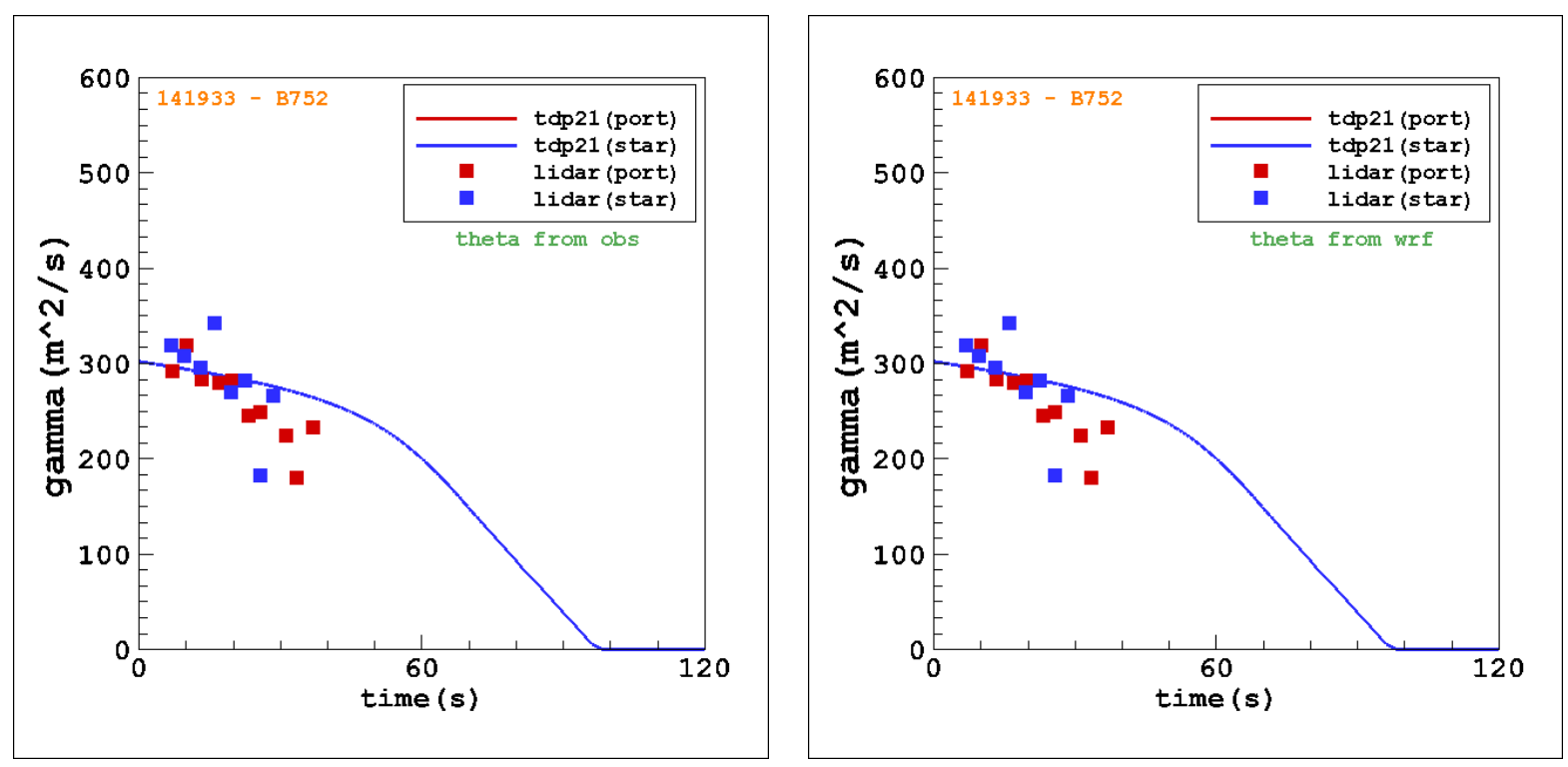

Figure 9. Comparison of TDP2.1 predicted wake vortex time histories with the observed CW Lidar data. The generating aircraft was a $\mathbf{B 7 5 2}$ in this case. The left panel shows TDP2.1 simulation initialized by observed potential temperature. The right panel shows TDP2.1 simulation initialized by WRF predicted potential temperature. Dallas-Fort Worth - October 3, 1997.
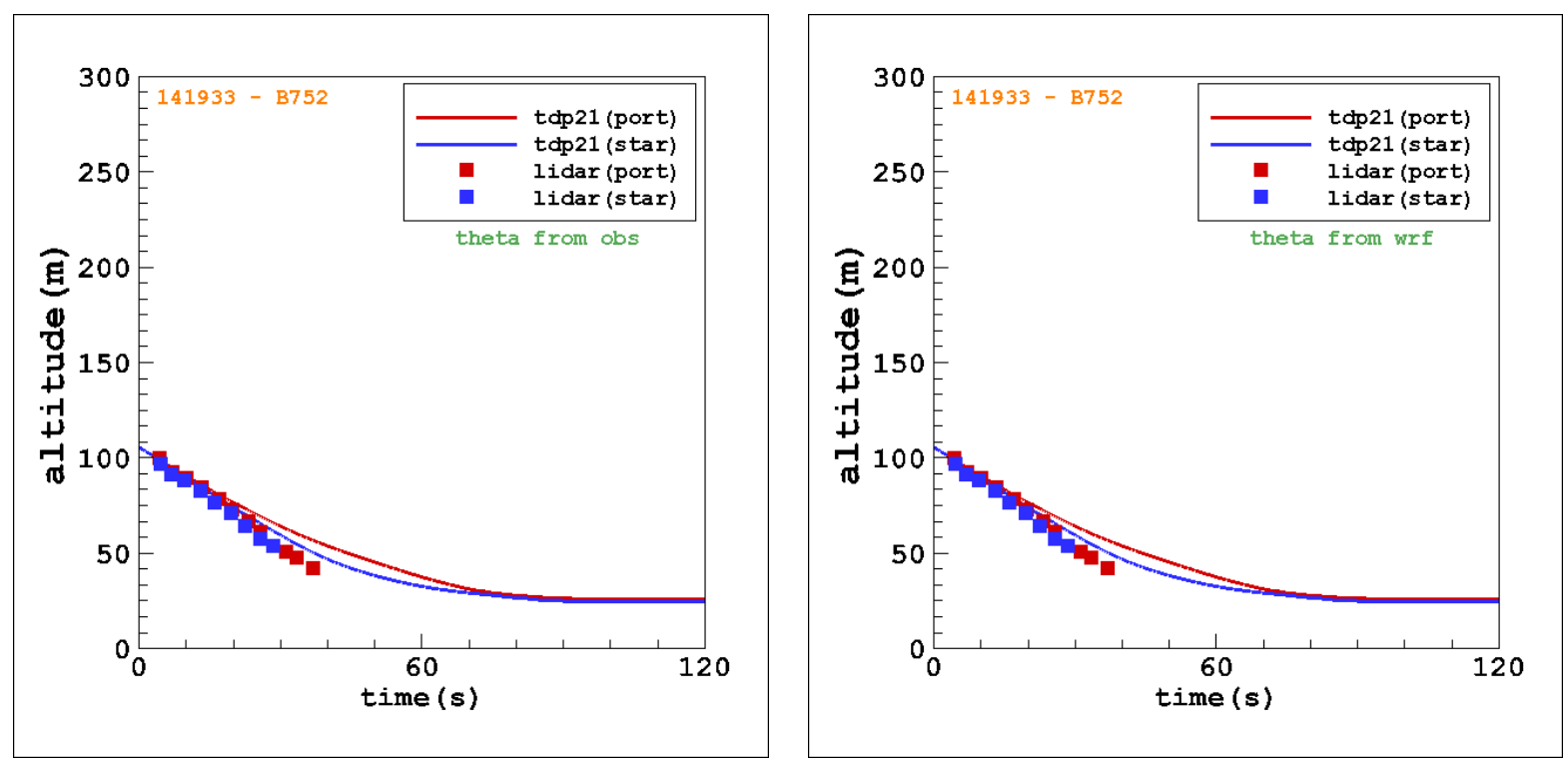

Figure 10. Comparison of TDP2.1 predicted wake vortex time histories with the observed CW Lidar data. The generating aircraft was a $\mathrm{B752}$ in this case. The left panel shows TDP2.1 simulation initialized by observed potential temperature. The right panel shows TDP2.1 simulation initialized by WRF predicted potential temperature. Dallas-Fort Worth - October 3, 1997. 


\section{Denver Wake Vortex Field Experiment}

\section{A. Denver Field Experiment}

The Denver field experiment was conducted by NASA during the month of September 2003. Although, the primary objective for this deployment was to evaluate wake measurements using acoustic sensors (Dougherty et al. 2004), wake trajectories and circulation were also measured using pulsed and continuous wave Lidars. In addition, temperature profiles were measured with the MTP5 sensor (microwave radiometer), and wind profiles from the pulsed Lidar measurements. During the Denver experiment, one minute average winds were measured by propeller anemometers that were mounted on a meteorological tower. The altitudes of the sensors were at $7 \mathrm{~m}, 14.6 \mathrm{~m}$, and $32.3 \mathrm{~m}$ AGL. In addition, wind measurements at a rate of $10 \mathrm{~Hz}$ were obtained with an ultrasonic anemometer that was mounted on a $7.3 \mathrm{~m}$ pole. Compared to the AVOSS deployments at Memphis (1995) and Dallas-Fort Worth (1997), the meteorological data collection at Denver was not as comprehensive. The generation of a vertical profile of eddy dissipation rate requires two data points at two different heights (Han 2000). In Denver 2003 experiment, there was only one sonic anemometer and therefore the profiles of eddy dissipation rates were obtained from the Lidar data using spatial structure functions (Pruis and Delisi 2011).

\section{B. WRF Simulation Setup}

The WRF simulation domain consisted of an outermost domain bounded between $130.25^{\circ} \mathrm{W}$ and $79.65^{\circ} \mathrm{W}$ in longitude and $24.48^{\circ} \mathrm{N}$ and $53.24^{\circ} \mathrm{N}$ in latitude with a horizontal mesh resolution of $12 \mathrm{~km}$. The inner high resolution domain was centered at Denver, Colorado and bounded between $115.71^{\circ} \mathrm{W}$ and $93.52^{\circ} \mathrm{W}$ in longitude and $32.77^{\circ} \mathrm{N}$ and $46.48^{\circ} \mathrm{N}$ in latitude with a horizontal mesh resolution of $4 \mathrm{~km}$. High-resolution $(1 \mathrm{~km})$ terrain and land use datasets were used for the innermost domain while lower resolution terrain was used in the coarser outer nest. A stretched grid with 90 levels was used in the vertical to provide high-resolution grid spacing in the boundary layer. The WRF computational domain is shown in Figure 11.

The Mellor-Yamada-Janjić turbulence scheme (Mellor and Yamada 1978; Janjić 1994) was used to parameterize sub-grid scale processes and higher-order schemes were used for computing the convective fluxes (fifth-order upwind-biased in the horizontal and third-order upwind-biased in the vertical). Fifth-order WENO scheme with positive definite limiter was used to transport microphysical scalars as well as turbulence kinetic energy. The simulation was initialized using the North American Regional Reanalysis (Mesinger et al. 2006) data from the NCDC at 0000UTC on September 19, 2003 and was run for a 24hr forecast. Data from the high-resolution inner nest were output every $15 \mathrm{~min}$.

\section{Comparison of WRF Predicted Temperature and Winds with Observations}

Several simulations were conducted for Denver (September 14 - September 20) in order to minimize the forecast errors. First, a set of sensitivity runs was conducted which included spinup time, microphysics scheme, radiation scheme, number of vertical levels, and horizontal mesh resolution. Spinup times of $3 h r, 6 h r$, and $12 h r$ degraded the solution and therefore the simulation was initialized at 0000UTC. The choice of microphysics scheme other than Thompson did not improve the forecast and in some cases degraded the solution. The choice of radiation schemes and horizontal mesh resolution did not improve the model forecast.

The WRF Data Assimilation Package (WRFDA) was also evaluated for Denver simulations. Data from the National Oceanic and Atmospheric Administration's (NOAA) Meteorological Assimilation Data Ingest System (MADIS) and surface and upper air observations from the NCAR archives were used in this study. The MADIS dataset included metars, satellite observations, mesonet data, raobs, Aircraft Communications Addressing and Reporting System (ACARS) data, and NOAA profilers. WRF options of Objective Analysis, Four-Dimensional Data Assimilation (Observational Nudging) and 3D Variational Analysis (Barker 2004) were tested. For the September 19, 2003 simulation, the four-dimensional data assimilation option resulted in an improvement in the forecast.

Figure 12 shows the comparison of simulated surface temperatures and winds with the ASOS data. The WRF data assimilation was used in this simulation. The forecast errors for the twenty-four hour period at Denver are listed in Table 5. The baseline simulation listed in Table 5 was initialized using gridded data only and the baselineton simulation used four-dimensional data assimilation with observational nudging. The errors in temperature and especially dew point temperature were reduced by using data assimilation. However, the error in $v$ component of wind increased slightly. Figure 12 shows that much of the error in temperature forecast was due to WRF's failure to capture the rapid decrease in temperature during the nighttime. 


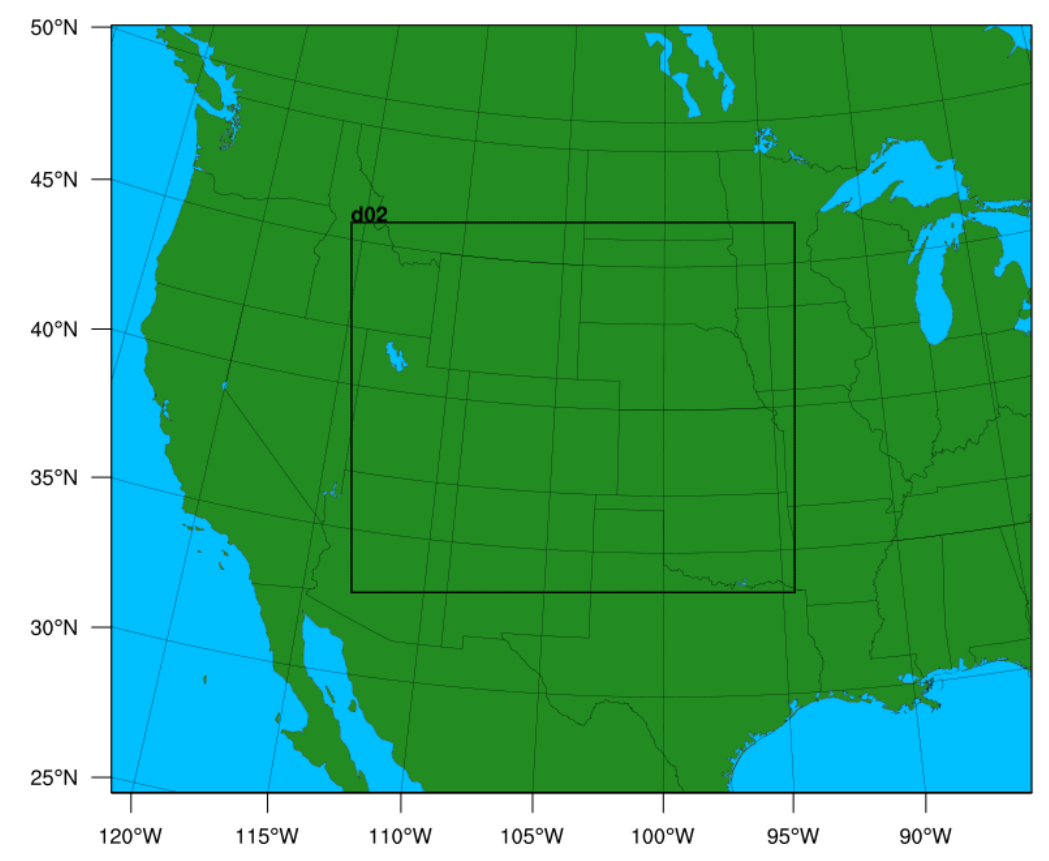

Figure 11. The WRF computational domain with higher resolution nest. The innermost nest had a resolution of $4 \mathrm{~km}$ and was centered at Denver, Colorado.
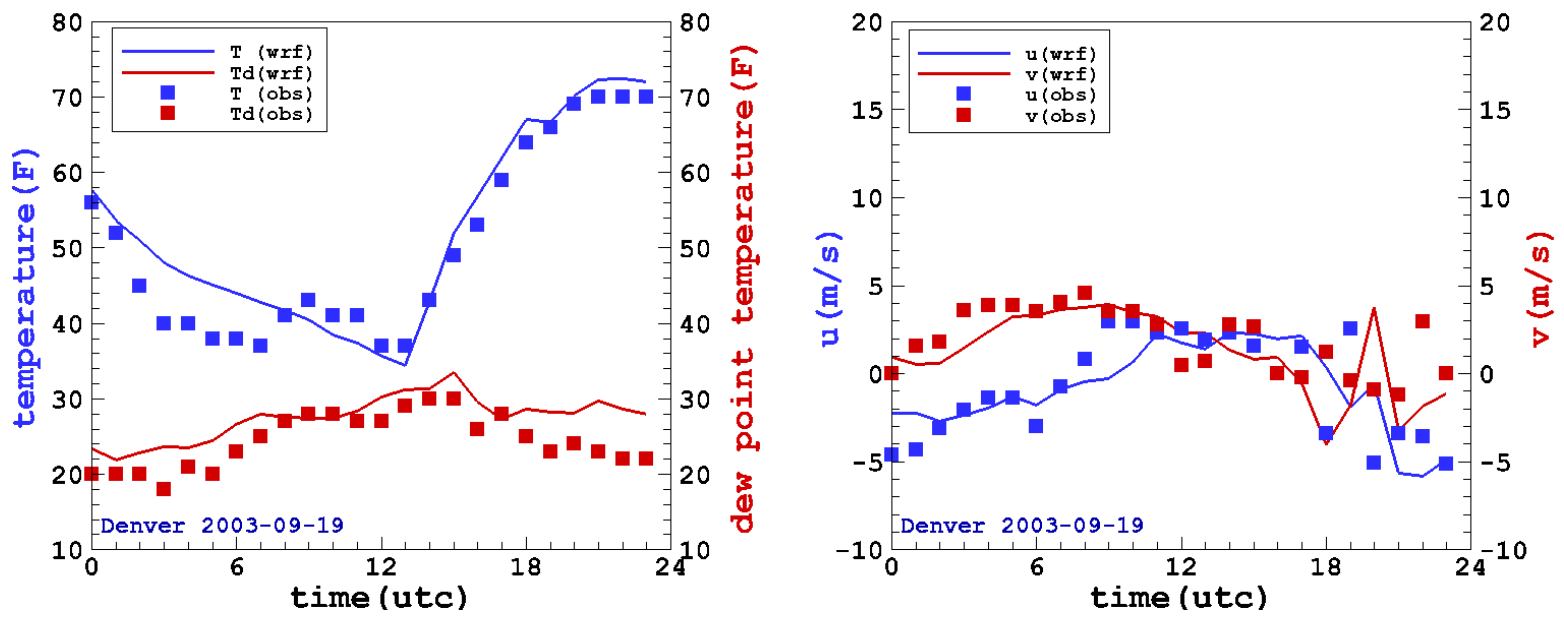

Figure 12. Comparison of WRF simulations with observations. WRF simulation results are denoted by solid lines. Observed temperatures at $2 \mathrm{~m}$ and observed winds at $10 \mathrm{~m}$ for Denver are shown as squares.

Table 5: WRF Surface Forecast Errors for Denver, Colorado (September 19, 2003)

\begin{tabular}{|c|c|c|c|c|c|c|c|c|c|c|c|c|}
\hline \multirow{2}{*}{ case } & \multicolumn{3}{|c|}{$\mathrm{T}\left({ }^{\circ} \mathbf{F}\right)$} & \multicolumn{3}{c|}{$\mathrm{T}_{\mathrm{d}}\left({ }^{\circ} \mathbf{F}\right)$} & \multicolumn{3}{c|}{$\mathrm{u}(\mathrm{m} / \mathrm{s})$} & \multicolumn{3}{c|}{$\mathrm{v}(\mathrm{m} / \mathrm{s})$} \\
\cline { 2 - 15 } & rmse & bias & mae & rmse & bias & mae & rmse & bias & mae & rmse & bias & mae \\
\hline baseline & 4.18 & $\mathbf{2 . 4 7}$ & $\mathbf{3 . 1 0}$ & $\mathbf{4 . 4 6}$ & $-\mathbf{- 2 . 7 3}$ & $\mathbf{3 . 9 8}$ & $\mathbf{1 . 9 1}$ & $-\mathbf{- 0 . 3 5}$ & $\mathbf{1 . 2 0}$ & $\mathbf{1 . 4 0}$ & $\mathbf{- 0 . 5 5}$ & $\mathbf{1 . 1 4}$ \\
\hline baseline + on & $\mathbf{3 . 8 7}$ & $\mathbf{2 . 1 5}$ & $\mathbf{3 . 2 1}$ & $\mathbf{3 . 6 9}$ & $\mathbf{3 . 0 5}$ & $\mathbf{3 . 1 9}$ & $\mathbf{2 . 0 3}$ & $-\mathbf{- 0 . 0 1}$ & $\mathbf{1 . 5 0}$ & $\mathbf{2 . 0 8}$ & $-\mathbf{- 0 . 6 4}$ & $\mathbf{1 . 5 4}$ \\
\hline
\end{tabular}




\section{Fast-Time Wake Transport and Decay Model Results}

A total of 82 landings for September 19, 2003 at Denver were used in this evaluation. The vertical profiles of temperature at Denver were measured by the MTP5 sensor, which is a microwave radiometer.

Two sets of simulations were conducted for each fast-time model: 1) the vertical profile potential temperature from observations was used, and 2) the vertical profile of the WRF-predicted potential temperature was used. A comparison of the average Brunt-Väisälä frequency from the observations and the WRF forecast is shown in Figure 13. The fast-time model predictions were then evaluated using CTI Pulsed Lidar observations. The results were quantified in terms of root-mean-square error, and are given in Table 6. All three models had relatively low errors for circulation and lateral transport.

A comparison of the TDP2.1 wake predictions with CTI Pulsed Lidar data is shown in Figures 14-15. The generating aircraft in this case was an MD83. The TDP2.1 predictions (initialized by observations and the WRF data) of circulation decay and vortex descent compare well with the Lidar measurements.

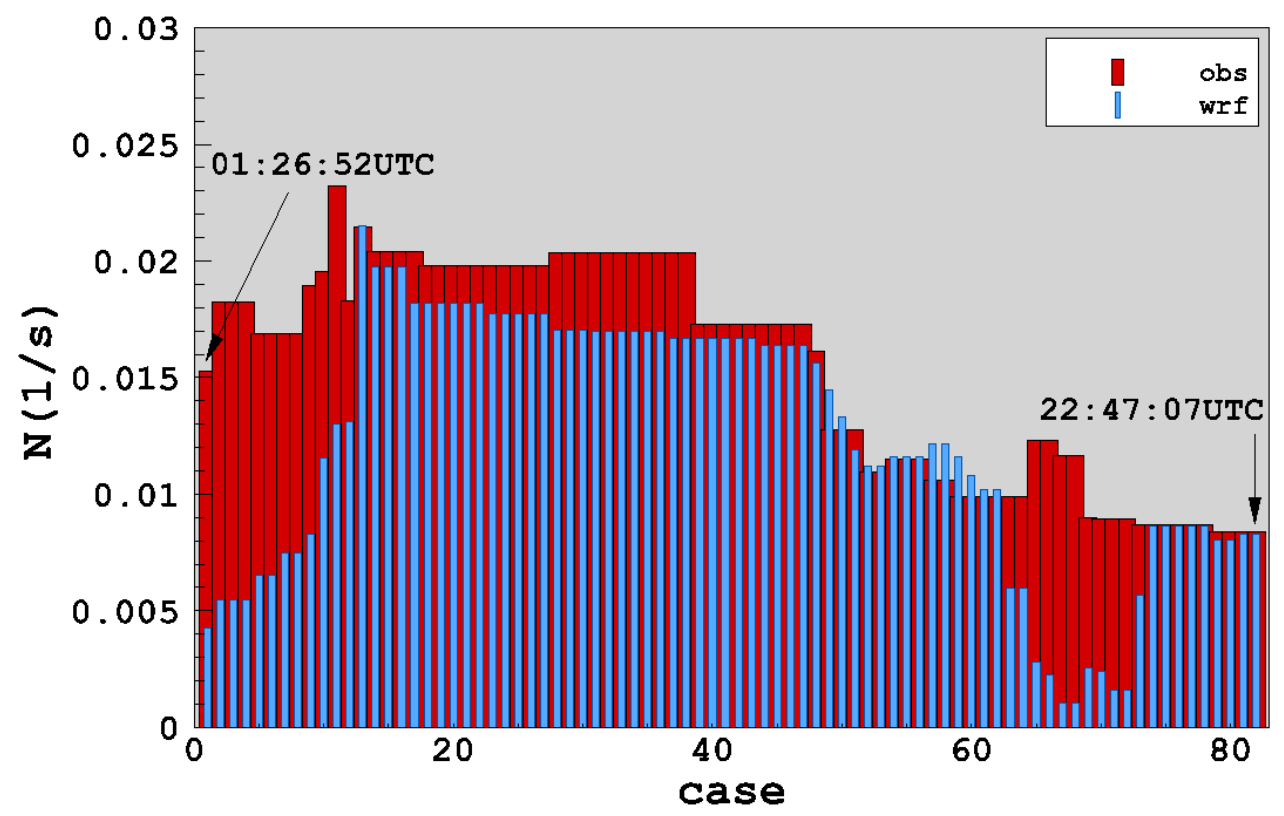

Figure 13. Comparison of the average Brunt-Väisälä frequency, $N\left(\mathrm{~s}^{-1}\right)$ for each vertical profile obtained from the WRF simulation and the observations. Denver - September 19, 2003.

Table 6: Fast-Time Models Evaluation (Mean RMSE) - Denver: September 19, 2003 (82 Cases)

\begin{tabular}{|c|c|c|c|c|c|c|}
\hline \multirow{2}{*}{ Model } & \multicolumn{2}{|c|}{$\begin{array}{c}\text { Circulation } \\
\left(\text { normalized by } \Gamma_{0}\right)\end{array}$} & \multicolumn{2}{c|}{$\begin{array}{c}\text { Lateral Transport } \\
\left(\text { normalized by } b_{0}\right)\end{array}$} & \multicolumn{2}{c|}{$\begin{array}{c}\text { Altitude } \\
\text { (normalized by } b_{0} \text { ) }\end{array}$} \\
\cline { 2 - 7 } & ICs from OBS & $\theta$ from WRF & ICs from OBS & $\theta$ from WRF & ICs from OBS & $\theta$ from WRF \\
\hline TDP2.1 & 0.211 & 0.228 & 0.616 & 0.626 & 0.874 & 0.868 \\
\hline APA3.2 & 0.218 & 0.209 & 0.620 & 0.621 & 0.933 & 0.913 \\
\hline APA3.4 & 0.184 & 0.195 & 0.613 & 0.615 & 0.926 & 0.930 \\
\hline
\end{tabular}



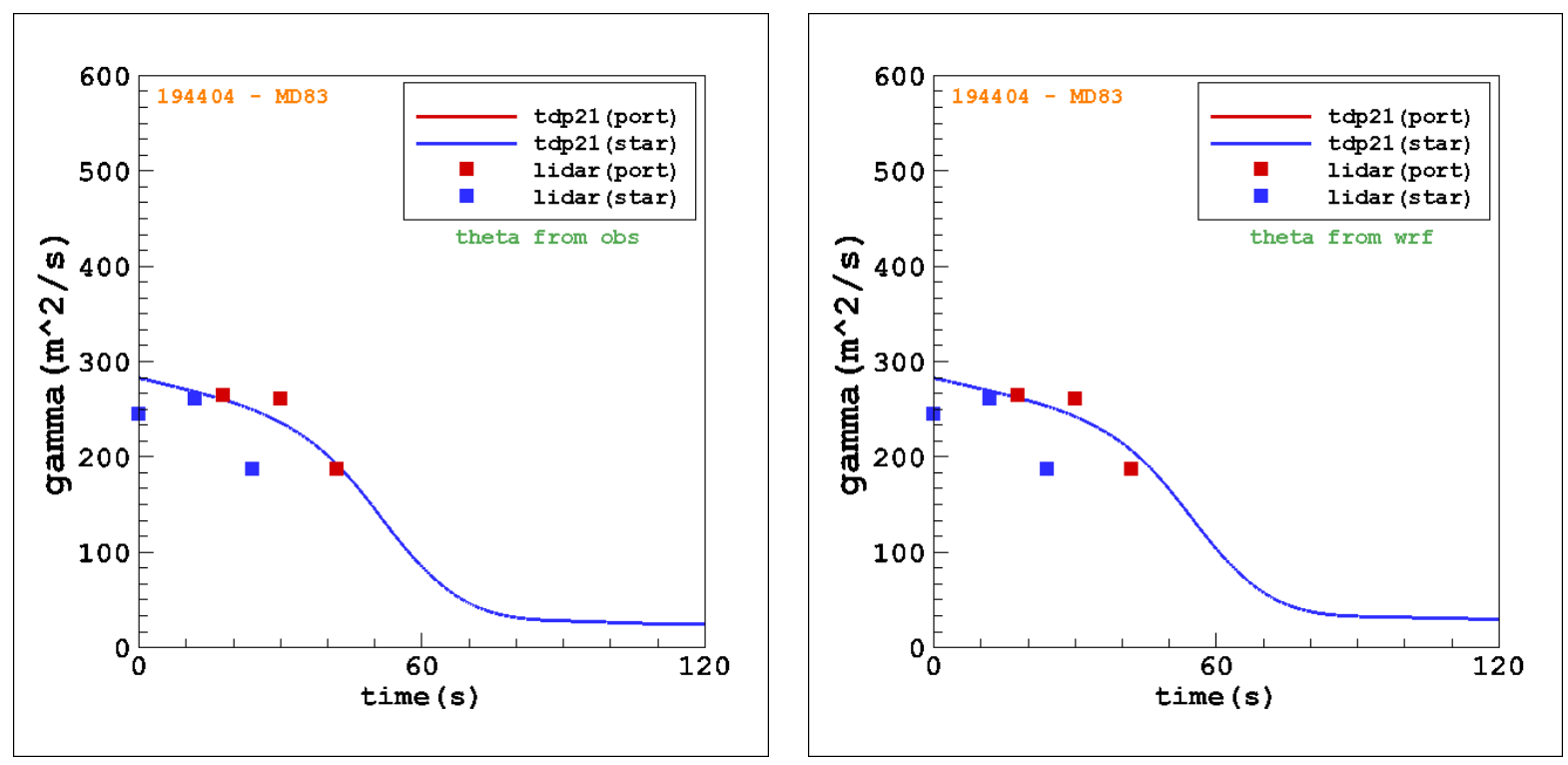

Figure 14. Comparison of TDP2.1 predicted wake vortex time histories with the observed CTI Pulsed Lidar data. The generating aircraft was an MD83 in this case. The left panel shows TDP2.1 simulation initialized by observed potential temperature. The right panel shows TDP2.1 simulation initialized by WRF predicted potential temperature. Denver - September 19, 2003.
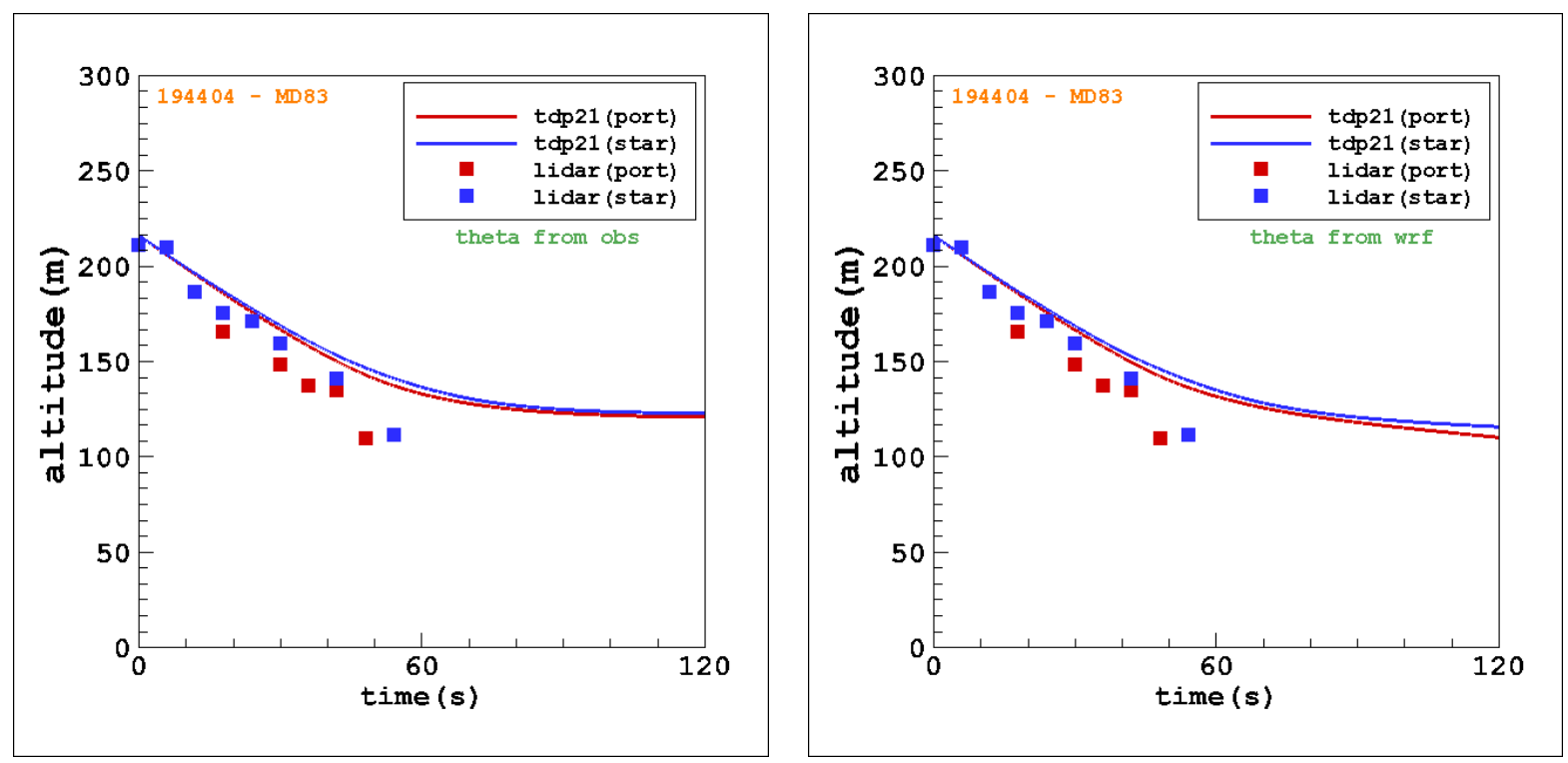

Figure 15. Comparison of TDP2.1 predicted wake vortex time histories with the observed CTI Pulsed Lidar data. The generating aircraft was an MD83 in this case. The left panel shows TDP2.1 simulation initialized by observed potential temperature. The right panel shows TDP2.1 simulation initialized by WRF predicted potential temperature. Denver - September 19, 2003. 


\section{Summary}

In this study, the state-of-the-art in mesoscale modeling was evaluated for supporting terminal area operations in general and wake vortex applications in particular. The National Center for Atmospheric Research's WRF mesoscale model was used to conduct simulations for three different geographical areas (Memphis, Tennessee; Dallas-Fort Worth, Texas; and Denver, Colorado). The WRF simulation data were evaluated against available observations with favorable results. The errors in surface temperature, dew point temperature, and wind speed and direction were relatively small for all three locations. The WRF forecasted stratification also compared well with observations - with the exception of Denver. In the case of Denver, WRF was unable to simulate the rapid cooling at surface during the nighttime and the level of stratification in the nighttime stable boundary layer.

Two sets of fast-time model simulations were conducted: 1) initialization using observed potential temperature profiles, and, 2) potential temperature profiles from WRF forecasts. The fast-time model predictions were compared against the Lidar measurements. In general, all three fast-time models (APA3.2, APA3.4, and TDP2.1) gave similar results with relatively low errors. The errors in fast-time models predictions were also low when initialized by WRF predicted potential temperature and comparable to errors in predictions initialized by observations. This study demonstrates the feasibility of using high-resolution mesoscale simulations for fast-time wake vortex modeling applications.

\section{Appendix A}

The model inputs specified in the simulations were based on the WRF sensitivity study conducted by Ahmad and Proctor (2012). The main input parameters used in the simulations are listed in this appendix.

Table A.1: Model Options used in WRF Simulations

\begin{tabular}{|c|c|c|c|}
\hline Model Option & Memphis (MEM) & Dallas/Fort Worth (DFW) & Denver (DEN) \\
\hline WRF Model Version & 3.2 .1 & 3.4 .1 & 3.4 .1 \\
\hline Initialization & $1995-08-15(1800 U T C)$ & $1997-10-03$ (0000UTC) & 2003-09-19 (0000UTC) \\
\hline Forecast Hours & $30 h r$ & $24 h r$ & $24 h r$ \\
\hline$\Delta x=\Delta y$ (Innermost nest) & $4 k m$ & $4 k m$ & $4 k m$ \\
\hline Vertical Levels & 60 & 60 & 90 \\
\hline Microphysics Scheme & Thompson & Thompson & Thompson \\
\hline PBL Scheme & Mellor-Yamada-Janjić & Mellor-Yamada-Janjić & Mellor-Yamada-Janjić \\
\hline Scalar Advection & Monotonic & $5^{\text {th }}$-order WENO & $5^{\text {th }}$-order WENO \\
\hline Initialization Data & NARR & NARR & NARR \\
\hline Data Assimilation & No & No & Yes \\
\hline
\end{tabular}

\section{Acknowledgments}

This work is sponsored under NASA's Concepts \& Technology Development (CTD) Project of the Airspace Systems Program. The WRF simulations were conducted on NASA Langley's K-cluster. 


\section{References}

Ahmad, N., and F. Proctor, "Estimation of Eddy Dissipation Rates from Mesoscale Model Simulations," American Institute of Aeronautics and Astronautics, AIAA-2012-0429.

Arakawa, A., V. R. Lamb, "Computational design of the basic dynamical process of the UCLA general circulation model”, Methods in Computational Physics, Vol. 17, 1977, pp. 173-265.

Bacon, D. P., N. N. Ahmad, Z. Boybeyi, T. J. Dunn, M. S. Hall, P. C. S. Lee, R. A. Sarma, M. D. Turner, K. Waight, S. Young, and J. Zack, “A Dynamically Adapting Weather and Dispersion Model: The Operational Multiscale Environment Model with Grid Adaptivity (OMEGA)”, Monthly Weather Review, Vol. 128, 2000, pp. 2044-2076.

Barker, D. M., W. Huang, Y. R. Guo, and Q. N. Xiao, “A Three-Dimensional (3DVAR) Data Assimilation System for use with MM5: Implementation and Initial Results", Monthly Weather Review, Vol. 132, 2004, pp. 897-914.

Benjamin, S. G., G. G. Grell, J. M. Brown, T. G. Smirnova, R. Bleck, "Mesoscale Weather Prediction with the RUC Hybrid Isentropic-Terrain-Following Coordinate Model”, Monthly Weather Review, Vol. 132, 2004, pp. 473-494.

Campbell, S.D., et al., "Wake Vortex Field Measurement Program at Memphis, TN Data Guide", Lincoln Laboratory, Massachusetts Institute of Technology. Project Report NASA/L-2. 1997.

Charney, J. J., M. L. Kaplan, Y. Lin, K. D. Pfeiffer, “A New Eddy Dissipation Rate Formulation for the Terminal Area PBL Prediction System (TAPPS)”, AIAA-2000-0624.

Chou, M. D., and M. J. Suarez, "A solar radiation parameterization for atmospheric studies", NASA Technical Report NASA/TM-1999-10460. 1999.

Corjon, A., and T. Poinsot, "Vortex Model to Define Safe Aircraft Separation Distances," Journal of Aircraft, Vol. 33, No.3, May-June 1996, pp. 547-553.

Dasey, T.J., et al., “Aircraft Vortex Spacing System (AVOSS). Initial 1997 System Deployment at Dallas/Ft. Worth (DFW) Airport”, Lincoln Laboratory, Massachusetts Institute of Technology. Project Report NASA/L-3. 1998.

Dougherty, R. P., F. Y. Wang, E. R. Booth, M. E. Watts, N. Fenichel, R. E. D’Errico, “Aircraft Wake Vortex Measurements at Denver International Airport," American Institute of Aeronautics and Astronautics, AIAA-2004-2880.

Dudhia, J., "A nonhydrostatic version of the Penn State/NCAR mesoscale model: Validation tests and simulation of an Atlantic cyclone and cold front”, Monthly Weather Review, Vol. 121, 1993, pp. 1493-1513.

Frech, M., F. Holzäpfel, A. Tafferner, T. Gerz, "High-Resolution Weather Database for the Terminal Area of Frankfurt Airport", Comptes Rendus Physique, Vol. 6, 2005, pp. 501-523.

Gerz, T., F. Holzäpfel, W. Bryant, F. Köpp, M. Frech, A. Tafferner, G. Winckelmans, "Research towards a wake vortex advisory for optimal aircraft spacing”, Journal of Applied Meteorology and Climatology, Vol. 46, 2007, pp. 1913-1932.

Greene, G. C., “An Approximate Model of Vortex Decay in the Atmosphere”, Journal of Aircraft, Vol. 23, 1986, pp. 566573.

Hinton, D. A., “Aircraft Vortex Spacing System (AVOSS) Conceptual Design”, NASA Technical Memorandum NASA-TM110184, 1995.

Han, J., S. P. Arya, S. Shen, Y. Lin, “An Estimation of Turbulent Kinetic Energy and Energy Dissipation Rate Based on Atmospheric Boundary Layer Similarity Theory”, NASA Contractor Report NASA-CR-2000-210298. 2000.

Holzäpfel, F., "Probabilistic Two-Phase Wake-Vortex Decay and Transport Model," Journal of Aircraft, Vol. 40, 2003, pp. 323-331.

Holzäpfel, F., "Minutes of the WakeNet3-Europe Workshop on Short-Term Weather Forecasting for Probabilistic WakeVortex Prediction”, Institut für Physik der Atmosphäre, Duetsches Zentrum für Luft- und Raumfahrt. April 2010.

Hodur, R.M., "The Naval Research Laboratory's Coupled Ocean/Atmosphere Mesoscale Prediction System (COAMPS)”, Monthly Weather Review, Vol. 125, 1997, pp. 1414-1430. 
Janjić, Z., "The Step-Mountain Eta Coordinate Model: Further Developments of the Convection, Viscous Sublayer, and Turbulence Closure Schemes”, Monthly Weather Review, Vol. 122, 1994, pp. 927-945.

Joseph, R., T. Dasey, R. Heinrichs, "Vortex and Meteorological Measurements at Dallas/Ft. Worth Airport," American Institute of Aeronautics and Astronautics, AIAA-1999-0760.

Kaplan, M. L., Y. Lin, C. J. Ringley, Z. G. Brown, M. T. Kiefer, P. S. Suffern, A. M. Hoggarth, "Wake Vortex Environment Simulations from a Terminal Area PBL Prediction System (TAPPS)", AIAA-2006-1074.

Kaplan, M. L., R. P. Weglarz, Y. Lin, D. B. Ensley, J. K. Kehoe, D. Decroix, “A Terminal Area PBL Prediction System for DFW", AIAA-1999-0983.

Klemp, J. B., W. C. Skamarock, and J. Dudhia, “Conservative Split-Explicit Time Integration Methods for the Compressible Nonhydrostatic Equations,” Monthly Weather Review, Vol. 135, 2007, pp. 2897-2913.

Liu, X., S. Osher, and T. Chen, "Weighted Essentially Non-Oscillatory Schemes," Journal of Computational Physics, Vol. 115, 1994, pp. 200-212.

Mellor, G. L., and T. Yamada, "Development of a turbulence closure model for geophysical fluid problems", Reviews of Geophysics and Space Physics, Vol. 20, 1982, pp. 851-875.

Mesinger, F., G. DiMego, E. Kalnay, K. Mitchell, P. C. Shafran, W. Ebisuzaki, D. Jović, J. Woollen, E. Rogers, E. H. Berbery, M. B. Ek, Y. Fan, R. Grumbine, W. Higgins, H. Li, Y. Lin, G. Manikin, D. Parrish, W. Shi, "North American Regional Reanalysis," Bulletin of the American Meteorological Society, Vol. 87, 2006, pp. 343-360.

Mesoscale and Microscale Meteorology Division, "Weather Research \& Forecasting ARW Version 3 Modeling System User's Guide", 2010, 352 pp. National Center for Atmospheric Research.

Mlawer, E. J., S. J. Taubman, P. D. Brown, M. J. Iacono, and S. A. Clough, "Radiative transfer for inhomogeneous atmosphere: RRTM, a validated correlated-k model for the longwave”, Journal of Geophysical Research, Vol. 102, 1997, pp. 663-682.

Perry, R. B., D.A. Hinton, and R.A. Stuever, “NASA Wake Vortex Research for Aircraft Spacing,” AIAA-1997-0057.

Proctor, F. H., “The Terminal Area Simulation System / Volume 1: Theoretical Formulation”, NASA Technical Report 4046. 1987.

Proctor, F.H., D. W. Hamilton, G. F. Switzer, "TASS Driven Algorithms for Wake Prediction," American Institute of Aeronautics and Astronautics, AIAA-2006-1073.

Proctor, F.H., "Evaluation of Fast-Time Wake Vortex Prediction Models," American Institute of Aeronautics and Astronautics, AIAA-2009-0344.

Pruis, M. J., and D. D. Delisi "Correlation of the Temporal Variability in the Crosswind and the Observation Lifetime of Vortices Measured with a Pulsed Lidar,” American Institute of Aeronautics and Astronautics, AIAA-2011-3199.

Ringley, C. J., Y. Lin, Z. G. Brown, M. L. Kaplan, “The Development of a Boundary Layer Turbulence Database for Wake Vortex Applications", American Institute of Aeronautics and Astronautics, AIAA-2007-287.

Robins, R.E., and D.P. Delisi, "NWRA AVOSS Wake Vortex Prediction Algorithm Version 3.1.1," NASA CR 2002-211746.

Sarpkaya, T., "New Model for Vortex Decay in the Atmosphere," Journal of Aircraft, Vol. 37, 2000, pp. 53-61.

Sarpkaya, T., R.E. Robins, and D.P. Delisi, "Wake-Vortex Eddy-Dissipation Model Predictions Compared with Observations," Journal of Aircraft, Vol. 38, 2001, pp. 687- 692.

Thompson, G., R. M. Rasmussen, K. Manning, "Explicit Forecasts of Winter Precipitation using an Improved Bulk Microphysics Scheme. Part1: Description and Sensitivity Analysis”, Monthly Weather Review, Vol. 132, 2004 , pp. 519-542.

de Visscher, I., G. Winckelmans, T. Lonfils, L. Bricteux, M. Duponcheel, N. Bourgeois, “The WAKE4D simulation platform for predicting aircraft wake vortex transport and decay: Description and examples of application," American Institute of Aeronautics and Astronautics, AIAA-2010-7994. 